\title{
Optimization of mechanical properties of fine-grained non-combustive magnesium alloy joint by asymmetrical double-sided friction stir welding
}

\author{
Juan Chen ${ }^{\text {a b }, *}$, Hidetoshi Fujii ${ }^{\text {a, }}$, Yufeng Sun ${ }^{\text {a }}$, Yoshiaki Morisada ${ }^{\text {a }}$, Katsuyoshi Kondoh ${ }^{\text {a }}$

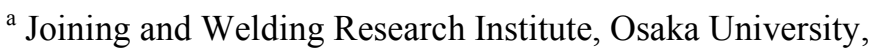 \\ 11-1 Mihogaoka, Ibaraki, Osaka 567-0047, Japan \\ ${ }^{\mathrm{b}}$ National Engineering Research Center of Light Alloy Net Forming and State Key Laboratory \\ of Metal Matrix Composite, Shanghai Jiao Tong University, 200030 Shanghai, PR China \\ *Corresponding author: Hidetoshi Fujii, \\ Email: fujii@jwwri.osaka-u.ac.jp
}

Phone number: 081-06-6879-8643; Fax number: 081-06-6879-8643

*Co-Corresponding author: Juan Chen

Email: cjuansmile@gmail.com

Phone number: 081-06-6879-8643; Fax number: 081-06-6879-8643

\begin{abstract}
The asymmetrical Double-sided Friction Stir Welding (DFSW) technique was applied to the fine-grained non-combustive AMX602 (Mg-6\%Al-0.5\%Mn-2\%Ca) magnesium alloy in order to tailor the appropriate crystallographic texture in the joint and maintain its mechanical properties. The diverse material flows caused by the different welding parameters affected the macrostructure of the DFSW joints. As the travel speed increased, the larger flash and the internal cavity disappeared, and the prior interface residue composed by a linear array of $\mathrm{Ca}$ oxide and adjacent coarse grains with lacking of $\mathrm{Ca}$ solute, which is a kind of joint defect due to excess heat input, became shorter. The complicated material flows caused by the asymmetrical layout of the double-sided tools produced a relatively weaker texture in the DFSW joint. In addition, compared with the one-sided FSW joint, the asymmetrical DFSW joint shows a relative higher strength since the microstructure in the joints maintains a fine grained structure with slight crystallographic isotropy.
\end{abstract}

Keywords: Non-combustive Magnesium alloy; Double-sided Friction Stir Welding; Texture; Tensile test http://www.elsevier.com/open-access/userlicense/1.0/ 


\section{Introduction}

Magnesium alloys have increasing interest for use in transport vehicle manufacturing due to their advantages of light weight and high specific strength (Yu et al., 2010), although they has some passive characteristics such as easy ignition and relatively low strength. Recently, in order to prevent easy ignition, calcium was added to the magnesium, which successfully produced the non-combustible magnesium alloys (Hakamada et al., 2010). Additionally, the strengthening of magnesium has also been achieved by several methods including, for example, the rapid solidification of the spinning water atomization process (SWAP) which is reported by Kondoh et al. (2010). The study of Elsayed et al. (2010) showed that SWAP can produce rapidly solidified powder particles with an ultra fine grained microstructure. Furthermore, the non-combustive magnesium alloy prepared by extruding the green compacts of the SWAP powders shows a remarkably high strength.

The scientific efforts for the development of magnesium manufacturing are being directed to the method of joining which is one of the most important processes to obtain structural products. However, according to the review by Mishra and Ma (2005), there are several problems with the welding of magnesium, such as the porosity and large distortion of the weld, that exist during the conventional fusion welding process of magnesium alloys. As a relatively new solid-state joining technique which is performed below the melting temperature of the material (Commin et al., 2009), friction stir welding (FSW) is able to overcome these problems since FSW is a solid state joining process (Xin et al., 2016). Additionally, due to the inhibited grain growth provided by the relatively lower heat input during the FSW, the ultrafine grained material is to be preferably welded by the FSW technique (Sun et al., 2009). On the other hand, it is well known that a magnesium alloy with the hcp structure has an occasional crystallographic texture with strong anisotropy and this causes severe anisotropic mechanical properties (Wang et al., 2006). A strong texture is presented even in the FSW joint of the Mg alloy, including the friction stir welded SWAP AMX602 Mg alloy in our previous study (Chen, et al., 2012). The textures of the FSW joints have completely different components of orientations in the different regions of the joint, as has been discussed by Park et al. 
(2003). As a result, the fracture during tensile test preferentially occurred in the regions with specific orientations (Park et al. 2003). This means that a method to produce more random texture in the joints should be developed.

Recently, the authors proposed that one of the possible methods to produce more random texture is the asymmetrical double-sided friction stir welding (asymmetrical DFSW) (Chen et al., 2013). The concept of DFSW was originally proposed by Thomas et al. (1995). In the original DFSW, the two FSW tools with probes were simultaneously used on both the upper and lower surfaces of the workpiece (Thomas et al., 1998). The possible benefit of the DFSW is that an enhanced welding speed can be achieved due to less heat loss through the support anvil. Although the bobbin tool FSW reported by Hilgert et al. (2011) has advantages similar to the DFSW, the DFSW has the possibility of more variations with separated double tools compared to the two fixed parts of the bobbin tool. In addition, comparing to the counter-rotating twin tool FSW which also can generate high heat reported by Kumari et al. (2015), the double tools adopted at the upper and lower side of the workpiece during DFSW can cause more intense plastic deformation in the processed zone. The authors have proposed the application of a different combination of tools to the DFSW, in which one of the tools is changed to a flat tool with no probe (Chen et al., 2013) or concave tool (Chen et al., 2016). In addition, the different tilt angles of the upper and lower tools can be set. This method can break the symmetrical metal flow and it should be useful to develop a random texture with maintaining the benefits in the original DFSW.

Although the advantages of the DFSW has been presented in previous works (Chen et al., 2013), the application of the asymmetrical DFSW is limited only to a specific magnesium alloy (AZ31). As already mentioned, the non-combustible magnesium alloy with a fine grained structure has the strong possibility to extend the industrial applications of magnesium. However, as is well known, the initial grain size (Chen et al., 2012) and the chemical composition (Bohlen et al., 2007) can have strong effect on the texture development, so that the efficiency of the asymmetrical DFSW on the texture randomization is still unclear. Consequently, the objective of the present study is to evaluate the microstructure evolution (especially the texture), of the double-sided friction stir welded 
fine-grained non-combustive AMX602 Mg alloy and obtain optimized mechanical properties of the fine-grained non-combustive AMX602 Mg alloy joint by the double-sided friction stir welding.

\section{Experimental procedure}

The fine grained non-combustive AMX602 plates used in this study have the chemical composition (in mass \%) of Mg-6\%Al-0.5\%Mn-2\%Ca. The as-received plate, fabricated through extruding the green compacts of the SWAP ultrafine grained powders, possesses nearly equiaxed grains of $1.2 \mu \mathrm{m}$ and a typical extruding texture with the $<0001>$ nearly parallel to the normal direction (ND) of the plane as mentioned later in detail. The dimensions of plates were $4 \mathrm{~mm}$ thick, $75 \mathrm{~mm}$ wide and $300 \mathrm{~mm}$ long. A schematic of the asymmetrical DFSW is illustrated in Fig. 1. The tool with a $15 \mathrm{~mm}$ shoulder diameter and a $5 \mathrm{~mm}$ threaded probe diameter with a $3.8 \mathrm{~mm}$ probe height was used as the upper tool. The upper tool was tilted 3० opposite of the welding direction (WD), which coincided with the extruding direction of the base material (BM). The lower tool had only a flat shoulder of $20 \mathrm{~mm}$ in diameter. Welds were made over a range of travel speeds from 300 to $500 \mathrm{~mm} / \mathrm{min}$ and at a constant rotation speed of 600rpm for the double tools. In this study, both the upper tool and lower tool rotated counterclockwise (CCW). For comparison, a one-sided FSW joint of the sample was fabricated by the optimum welding parameters $(1100 \mathrm{rpm}$ rotating speed, $300 \mathrm{~mm} / \mathrm{min}$ travel speed) indicated in a previous study (Chen et al., 2012).

A microstructural characterization was performed at a cross section of the joint perpendicular to the WD. The specimens were mechanically ground and polished, and then etched with a mixture of $10 \mathrm{~g}$ picric acid, $175 \mathrm{ml}$ ethanol, $25 \mathrm{ml}$ acetic acid, and $25 \mathrm{ml}$ distilled water for the observation by optical microscopy (OM) and scanning electron microscopy (SEM). To evaluate the texture development during the DFSW, the samples mechanically polished followed by ion milling were examined by the electronic backscattering diffraction (EBSD) technique in an SEM equipped with a field emission gun operated at $15 \mathrm{kV}$. Transmission electron microscopy (TEM, $200 \mathrm{kV}$ ) was also used to observe the stir zone (SZ) of the joint. The TEM specimens were prepared by focused ion beam. The composition of the particles existing in the $\mathrm{SZ}$ of the joint and elemental mapping was 
done by a TEM equipped with an energy dispersive X-ray spectroscopy (EDS) analysis system and an electron probe microanalyzer (EPMA).

Following the FSW and DFSW, the Vickers hardness profile of the weld was measured on the middle thickness line of the transverse cross-section. The tensile test was carried out using the Instron tensile tester with a crosshead speed of $1 \mathrm{~mm} / \mathrm{min}$. Tensile direction was perpendicular to the WD. Three tensile specimens were cut in the longitudinal direction perpendicular to the WD. All specimens were dog bone in shape, $50 \mathrm{~mm}$ (gauge length) $\times 12 \mathrm{~mm}$ (width) in the gauge area.

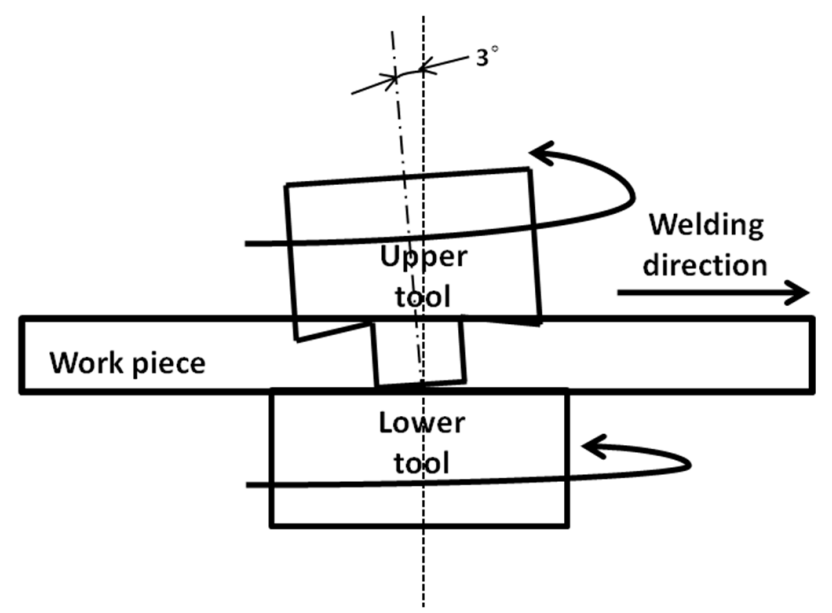

Fig. 1 Schematic illustration of the asymmetrical double-sided friction stir welding.

\section{Results and discussion}

\subsection{Cross-sectional macrostructure of the joints}

The cross-sectional macrostructure of the one-sided FSW joint using the optimum welding parameters and the asymmetrical DFSW welded joints prepared at different travel speeds on the SWAP AMX602 Mg alloy are presented in Fig. 2. Compared to the conventional FSW joint (a) in which the typical onion ring pattern (as reported by Morisada et al., 2007) was observed in the stir zone, the shapes of the onion ring changed and showed a less symmetrical morphology in the DFSW joints welded at the $500 \mathrm{~mm} / \mathrm{min}$ travel speed (c). It is reported that the onion ring is mainly caused by the metal flow (Arbegast, 2008), so that the collapse of the onion ring in the asymmetrical DFSW suggests turbulence of the metal flow. 


\begin{tabular}{|c|c|}
\hline Welding Parameters & Cross-section macrostructure \\
\hline $\begin{array}{c}\text { One-sided FSW } \\
1100 \mathrm{rpm} 300 \mathrm{~mm} / \mathrm{min}\end{array}$ & (a) AS \\
\hline $\begin{array}{l}\text { Double-sided FSW } \\
600 \mathrm{rpm} 300 \mathrm{~mm} / \mathrm{min}\end{array}$ & (b) 2 prior interface residue $\mathrm{RS}$ \\
\hline $\begin{array}{l}\text { Double-sided FSW } \\
600 \mathrm{rpm} 500 \mathrm{~mm} / \mathrm{min}\end{array}$ & 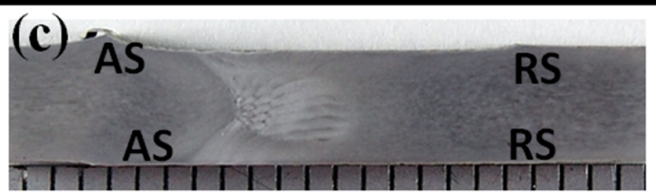 \\
\hline
\end{tabular}

Fig. 2 Transverse cross-sectional macrostructures of SWAP AMX602 Mg alloy joints obtained by one-sided FSW (a) and the asymmetrical DFSW at the travelling speed of $300 \mathrm{~mm} / \mathrm{min}$ (b) or 500 $\mathrm{mm} / \mathrm{min}$ (c). The notations of AS-m, SM-m and RS-m in (a) indicates the EBSD measurement points as shown in Fig. 8.

The different travel speeds during the DFSW showed an effect on the structure of the joints. Concerning the DFSW $300 \mathrm{~mm} / \mathrm{min}$ joint (b), plenty of flash at the surface, an internal cavity on the advance side (AS, as shown more clearly in the insert map) and a special line in the SZ (marked by the dashed ellipse) which may be on the initial butt surface were found. As will be shown later, the special line can be regarded as a trace of the interface between the two base metal sheets, so that the special line is referred to as a "prior interface residue" in this paper. As the travel speed increased, the larger flash and the internal cavity disappeared, and the prior interface residue became shorter. Generally, the excess heat input caused by the smaller travel speed lead to the larger mass (Kim et al., 2006). The unbalance mass flux due to the abnormal material flow generated the internal cavity (Mishra and Ma 2005) and the increasing forward travel speed can increase the downward pumping of the top part material into the zone at AS in which the cavity easily occurs (Kim et al., 2006). Therefore, the joints without a cavity were obtained at the higher travel speed of $500 \mathrm{~mm} / \mathrm{min}$. 


\subsection{Microstructure of the joints}

The OM micrographs of the BM (a) and the DFSW joint (b, c, d) are shown in Fig. 3. The microstructure of the thermomechanically affected zone (TMAZ, as shown in Fig. $\mathbf{3}$ (b) ), which is the boundary zone between the BM and SZ, the SZ (as shown in Fig. 3 (c) ) and that with the prior interface residue (Fig. 3 (d)) of the DFSW joint welded at 600 rpm rotation speed and 300 $\mathrm{mm} / \mathrm{min}$ travel speed are presented. The BM (as shown in Fig. 3 (a)) exhibited an ultrafine grain structure whose mean grain size was $1.2 \mu \mathrm{m}$, and a majority of the fine particles that had combined with a few larger particles was also observed. The fine particles were identified as $\mathrm{Al}_{2} \mathrm{Ca}$ (Elsayed et al., 2010). The larger particles were produced during the atomaization process and identified as $\mathrm{MgO}$ and/or $\operatorname{Mg}(\mathrm{OH})_{2}$ ( Liao et al., 2012). The TMAZ (as shown in Fig. 3 (b)) of the DFSW joint is characterized by slightly coarser grains than that of the BM. This is similar to the results of the one sided FSW as shown in the previous study (Chen et al., 2012). Almost the same morphology can be found in the entire part of the SZ (Fig. 3 (c)). On the other hand, the prior interface residue in SZ (Fig. 3 (d)) exhibits a linear array of particles and adjacent significantly coarser grains with fewer precipitates.
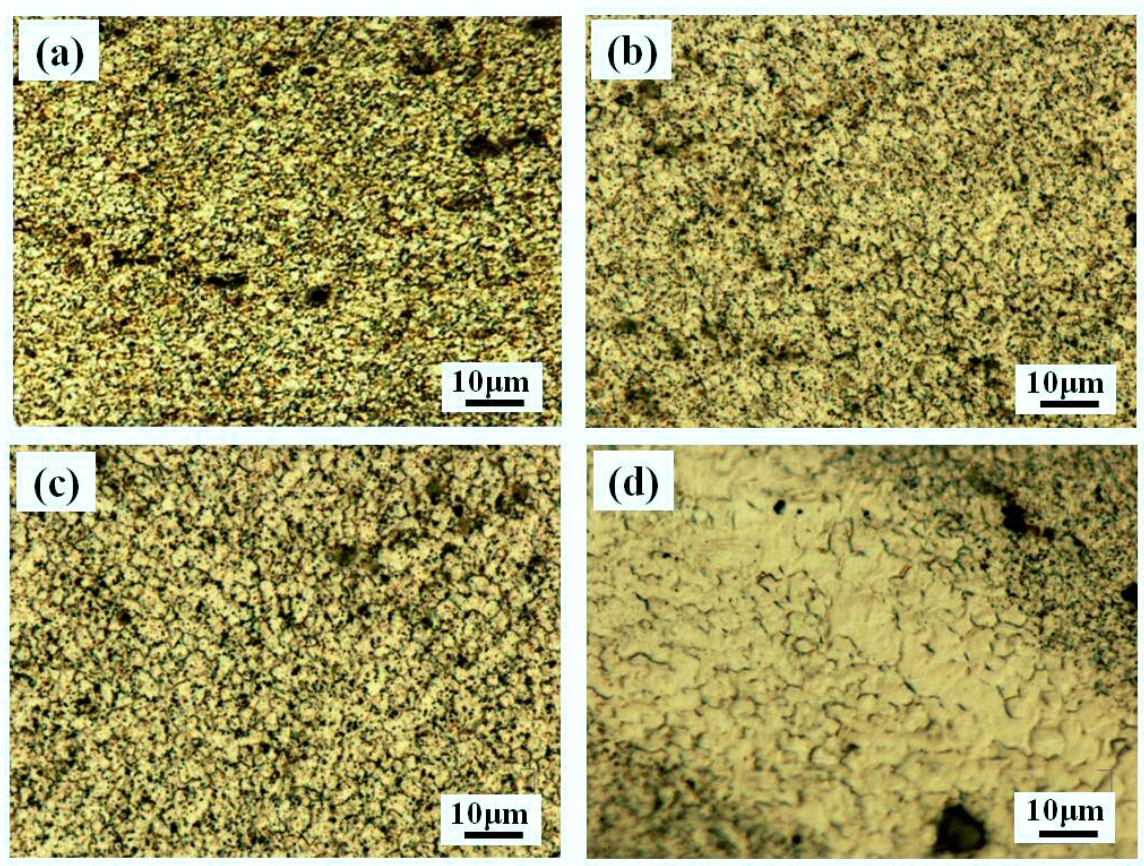

Fig. 3 Optical micrographs of the base material (a) and the asymmetrical DFSW joint: TMAZ (b); SZ (c) and that with the prior interface residue (d). The DFSW was conducted at 600rpm rotation 
speed and $300 \mathrm{~mm} / \mathrm{min}$ travel speed.

Fig. 4 shows TEM results of the AMX602 base material (Fig.4 (a, c, e, f)) and the central part of SZ in the DFSW joint welded by $500 \mathrm{~mm} / \mathrm{min}$ (Fig. 4 (b, d)). From the electron diffraction patterns of Particle A (Fig. 4 (e)) and Particle B (Fig. 4 (f)) as marked by red arrows in Fig. 4 (c), it indicates that the particles in the AMX602 alloys are identify to be $\mathrm{Al}_{2} \mathrm{Ca}$ and $\mathrm{Al}_{6} \mathrm{Mn}$. By comparing Fig. 4 (a, c) and Fig. 4 (b, d), it can be found that the grain size in the SZ increased while the density and the size of the precipitated phases did not change much after the DFSW.
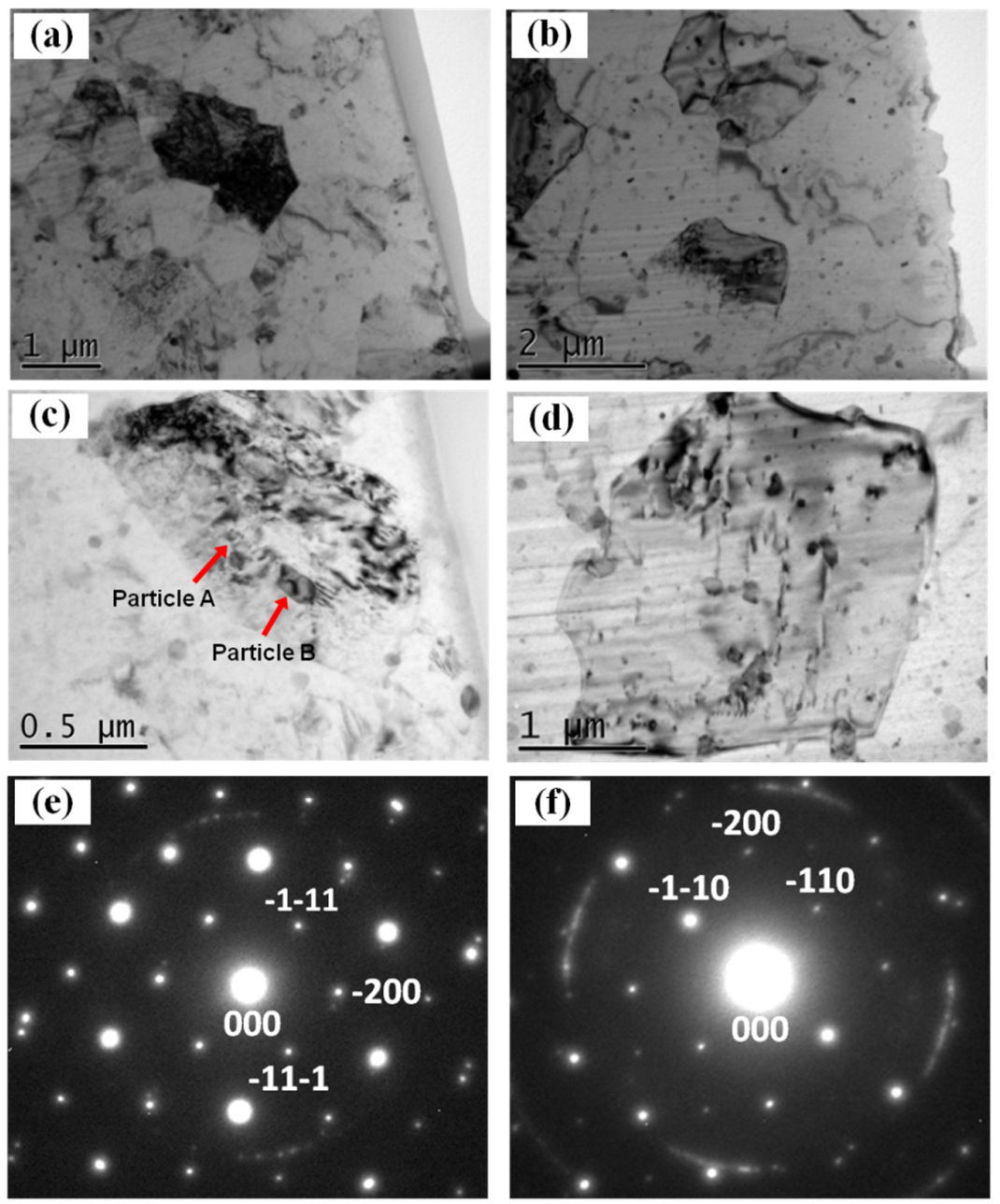

Fig. 4 TEM image showing the microstructure of BM (a, c); central part of SZ in the DFSW joint welded by $500 \mathrm{~mm} / \mathrm{min}$ (b, d). (e) and (f) are the electron diffraction patterns of Particle A and 
Particle B as marked by red arrows in (c), respectively.

In order to examine the prior interface residue in detail, an EPMA analysis was performed to reveal the elemental distribution of $\mathrm{Ca}, \mathrm{Al}, \mathrm{O}$ in the $\mathrm{DFSW}$ joint obtained at the $300 \mathrm{~mm} / \mathrm{min}$ travel speed. Fig. 5 (a) shows SEM images of the prior interface residue at the top of the joint. This observation clarified that the prior interface residue consists of a coarse grain region with a width of around $50 \mu \mathrm{m}$ and a linear array of white particles. The EPMA mapping (b) indicated the enrichment of $\mathrm{Ca}$ and $\mathrm{O}$ in the particle locations, indicating that the particles in the prior interface residue are $\mathrm{Ca}$ oxide. On the other hand, a relatively smaller amount of $\mathrm{Ca}$ and $\mathrm{O}$ elements are found in the coarse grain region. As is well known, $\mathrm{Ca}$ is easily oxidized, so that $\mathrm{Ca}$ oxide rapidly grew at the initial butt surface with some diffusion of $\mathrm{Ca}$ from the interior to the surface.
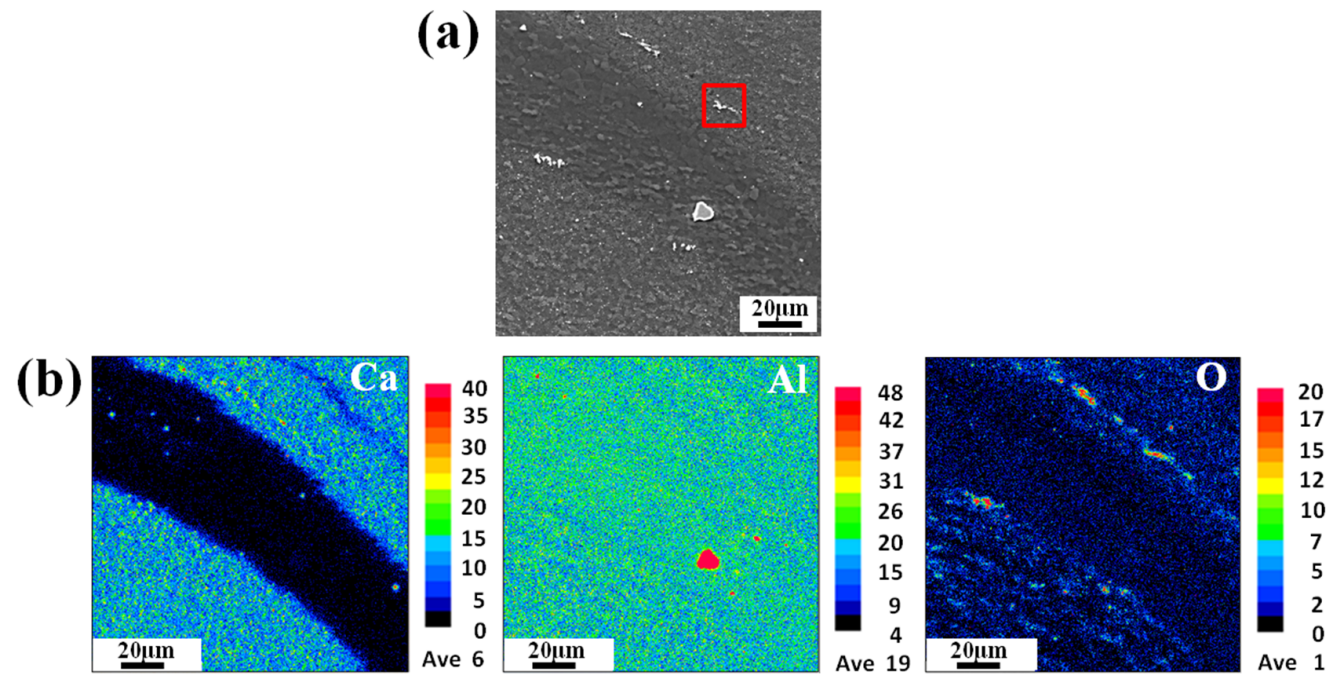

Fig. 5 SEM micrograph (a) and corresponding EPMA maps of $\mathrm{Ca}, \mathrm{Al}$ and $\mathrm{O}$ (b) of the SZ with the prior interface residue in the DFSW joint obtained at $300 \mathrm{~mm} / \mathrm{min}$ travel speed.

In order to accurately characterize the microstructure, an EDS (equipped in TEM) elemental mapping of the linear array of particles in the prior interface residue shown in the joint welded at a $600 \mathrm{rpm}$ rotation speed and $300 \mathrm{~mm} / \mathrm{min}$ travel speed was conducted. Fig. 6 shows the bright field image (a) and the EDS element map of $\mathrm{Al}$ (b), $\mathrm{Ca}$ (c) and $\mathrm{O}(\mathrm{d})$. This observation shows that a large amount of the $\mathrm{Ca}$ and $\mathrm{O}$ elements was distributed in the prior interface residue. This means that the 
particles present in the prior interface residue are a $\mathrm{CaO}$ compound as was shown by the EPMA results (Fig. 5). Consequently, the prior interface residue is formed due to the oxidization of Ca during the DFSW and shows two parts as linear array of $\mathrm{CaO}$ particles and adjacent coarser grains with less Ca solute. This is consistent with the result that the prior interface residue becomes smaller when the heat input is reduced $(500 \mathrm{~mm} / \mathrm{min}, \mathbf{F i g} .2)$. The grain growth in the prior interface residue is probably due to the lack of the solute drag effect of $\mathrm{Ca}$ on the movement of the grain boundaries.
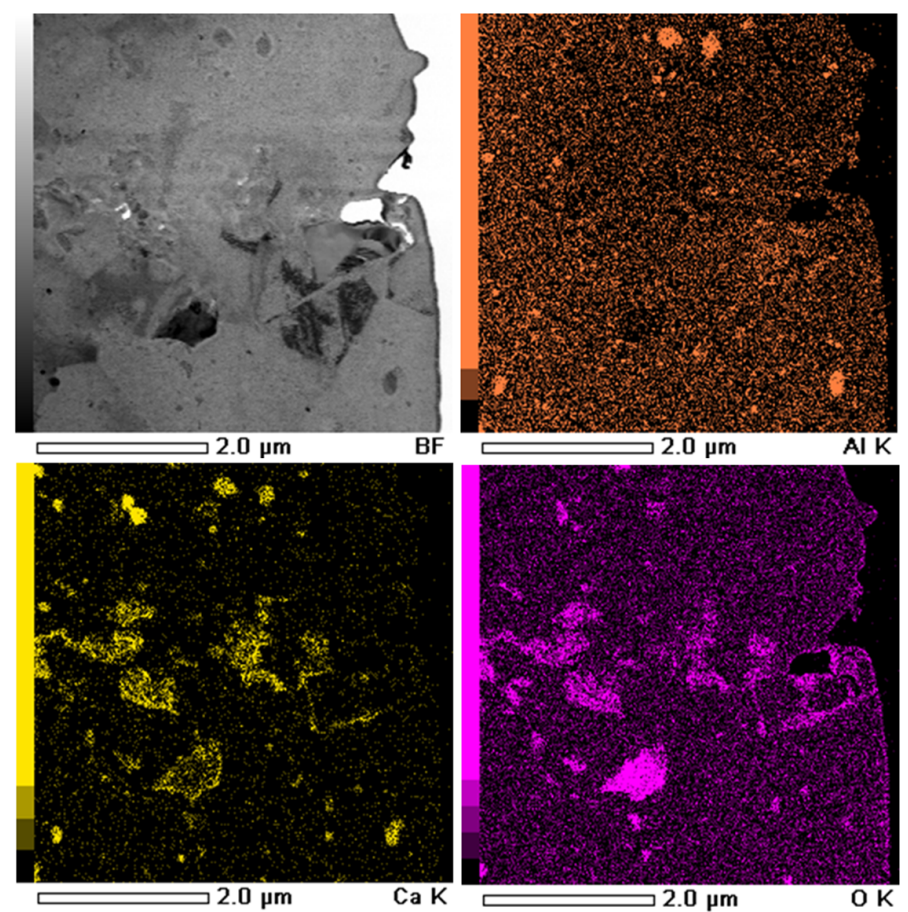

Fig. 6 EDS/TEM elemental mapping of the prior interface residue in the stir zone of DFSW joint welded at 600rpm and 300mm/min: Bight field image (a) and the EDS map of Al (b), Ca (c) and O (d).

\subsection{Texture inhomogeneity}

As described in the previous section, the sound joint was successfully obtained by the asymmetrical DFSW at the travelling speed of $500 \mathrm{~mm} / \mathrm{min}$ due to the optimum heat input, so that the texture of the joint examination was examined in detailed at $500 \mathrm{~mm} / \mathrm{min}$ along with comparison to the one-sided FSW.

Fig. 7 is the orientation color map showing the extruding direction (a) and the $\{0001\}$ and $\{10-10\}$ 
pole figures (b) of the SWAP AMX602 base material. The black line in the color map indicates high angle grain boundaries with a misorientation angle higher than $15 \circ$. The base material shows a fine equiaxied grain structure with an average grain size of $1.2 \mu \mathrm{m}$ and a few extra large grains can also be found. As is shown in the pole figures (Fig. 7 (b)), the base material shows the typical extruding texture where the 0001 axis is preferentially aligned parallel to the ND.
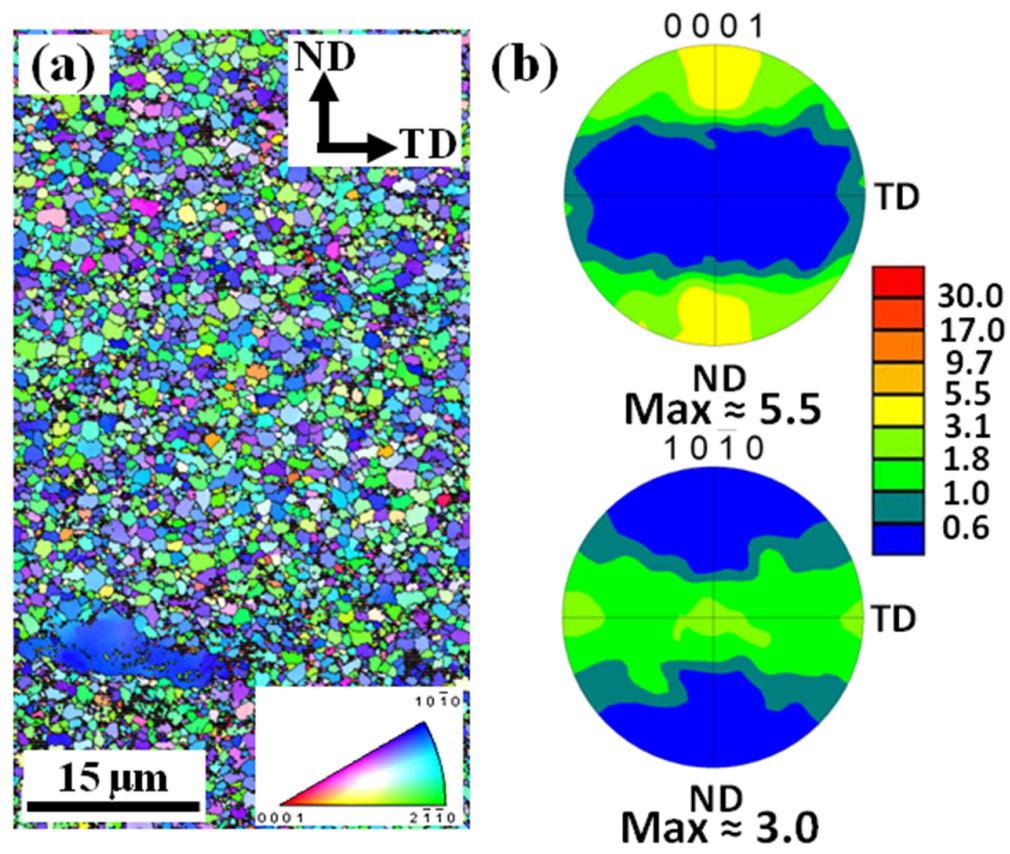

Fig. 7 Orientation color map showing the microstructure (a) and the corresponding pole figures (b) of the SWAP AMX602 base material.

The crystallographic orientation distribution of the one-sided FSW is shown in Fig. 8. The WD orientation color maps at the AS (a), the SZ (b) and the RS (c) were measured in the areas AS-m, SZ-m and RS-m, respectively, which were denoted in Fig. 2 (a). The grain sizes of these areas became slightly larger than that of the base metal. This result was similar to the optical observation and TEM results (Fig. 3 and Fig. 4) and was due to the recrystallization and grain growth during and/or after the FSW. The local textures of the AS, SZ and RS are shown in the pole figures of Fig. 8 (d, e, f). In these pole figures, the WD is aligned towards the upper surface from the back surface of the paper. The $\{0001\}$ and $\{10-10\}$ pole figures in these areas (d, e, f) indicated the strong accumulations of the $<0001>$ directions. The geometry of the $<0001>$ changes with the different 
measurement point and it seems that the $<0001>$ tends to align perpendicular to the side surface of the probe. This tendency well agrees with the previous report about the one-sided FSW joint of magnesium (Park et al., 2003).

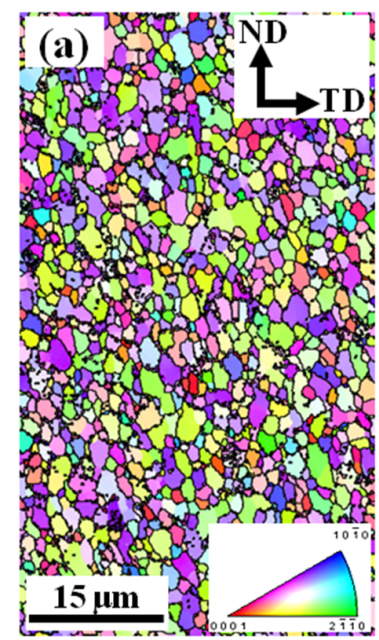

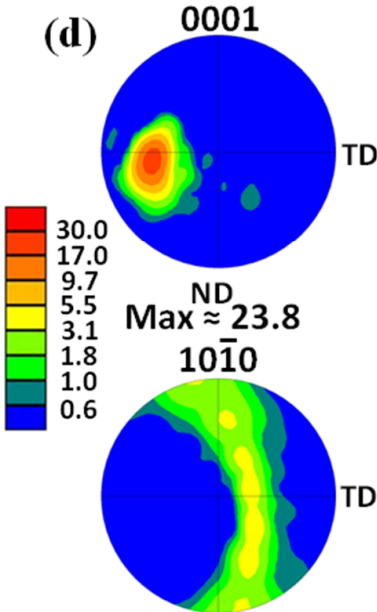

$\operatorname{Max} \approx 4.9$

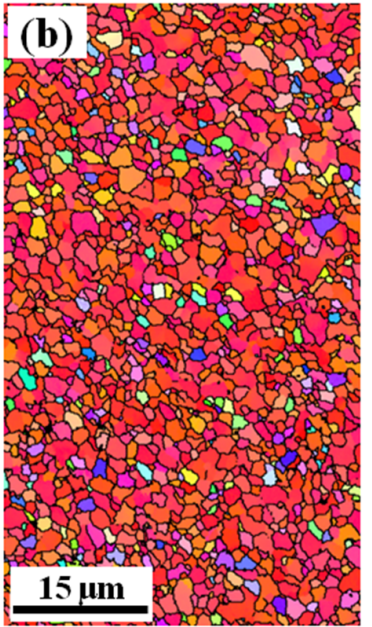

(e)

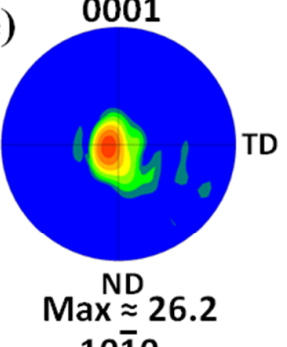

$10 \overline{1} 0$

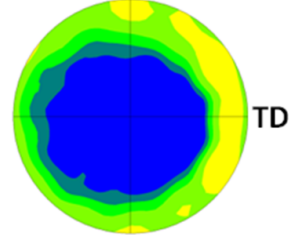

ND

$\operatorname{Max} \approx 5.0$

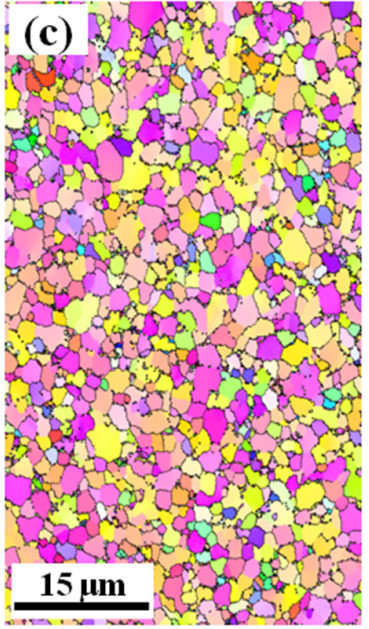

(f)

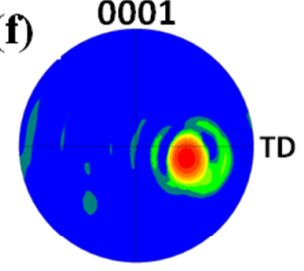

ND

$\operatorname{Max} \approx 46.8$

$10 \overline{1} 0$

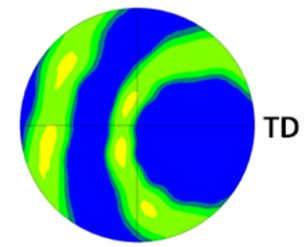

$\operatorname{Max} \approx 3.9$

Fig. 8 Orientation color map showing the microstructure of AS, SZ and RS (a, b, c) and the corresponding pole figures (d, e, f) of the AMX602 joint obtained by the one-sided FSW. The data were measured by EBSD at the positions AS-m (a, d), SZ-m (b, e) or RS-m (e, f) indicated in Fig. 2.

On the other hand, the EBSD measurement of the asymmetrical DFSW joint clarified the different characteristics as shown in Fig. 9. The EBSD data were obtained at the positions AS-c, SZ-c and RS-d as shown in Fig. 10 and these data are displayed in the same manner as Fig. 8. As is clarified 
in the orientation color maps (Fig. $\mathbf{9}(\mathbf{a}, \mathbf{b}, \mathbf{c})$ ), the average grain sizes of the AS, SZ and RS are 1.9 $\mu \mathrm{m}, 1.9 \mu \mathrm{m}$ and $2.0 \mu \mathrm{m}$, respectively, which are slightly larger than those of the one-sided FSW (Chen et al., 2012). This is probably due to the additional heat input from the bottom flat tool. The pole figures (Fig. 9 (d, e, f)) of the asymmetrical DFSW joint showed the significant difference from the one-sided FSW joint. The accumulation of the $<0001>$ directions almost disappeared in all three parts. Although the SZ (Fig. 9 (e)) shows the some accumulation of $<0001>$ in the direction similar to that of the one-sided FSW, the maximum intensity of the accumulation significantly decreases. Furthermore, at both the AS (Fig. 9 (d)) and RS (Fig. 9 (f)), these textures were completely changed with a reduced maximum intensity of the orientation accumulation.
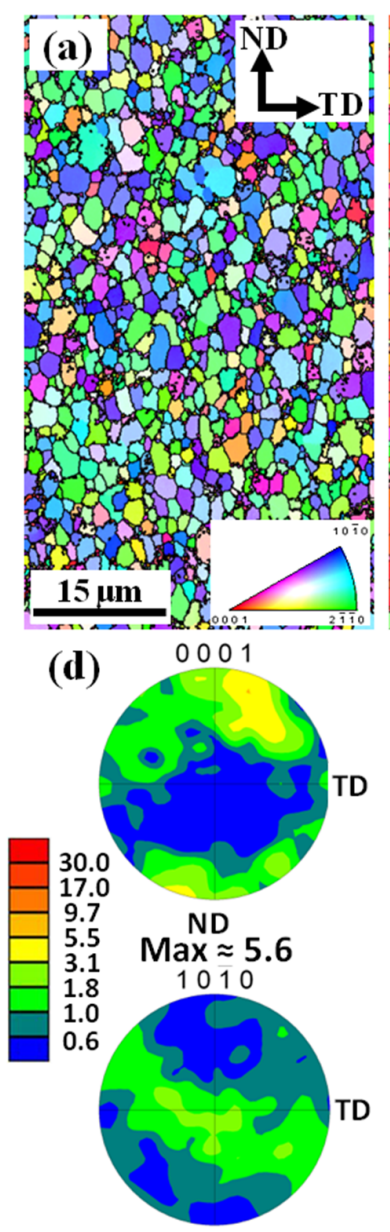

$\operatorname{Max} \approx 2.4$

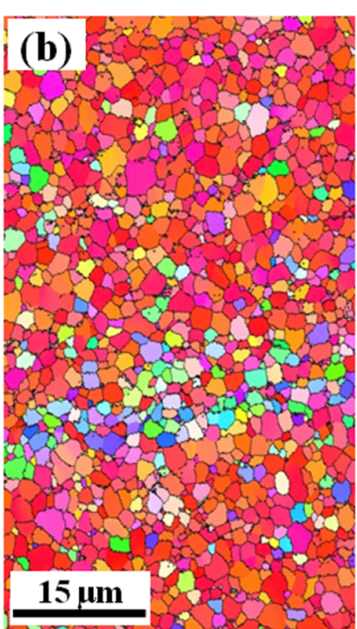

(e)

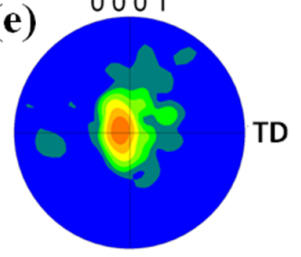$$
\text { ND }
$$

$\operatorname{Max} \approx 16.9$

1010

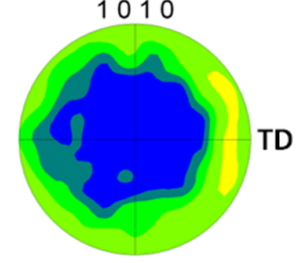

ND

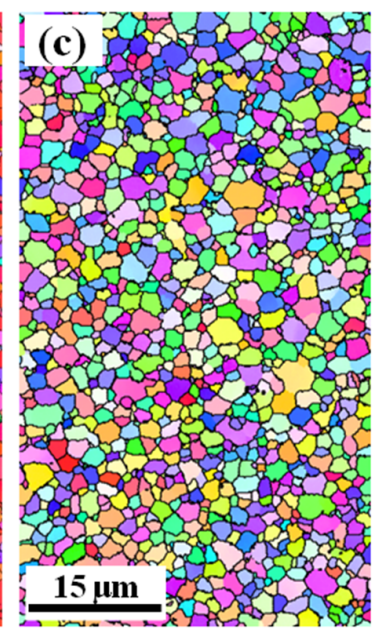

(f) 0001

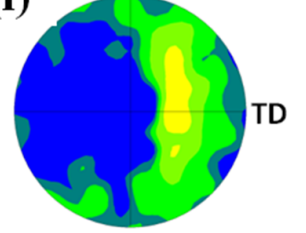

$\underset{\operatorname{Max}}{\mathrm{ND}} \approx 5.3$

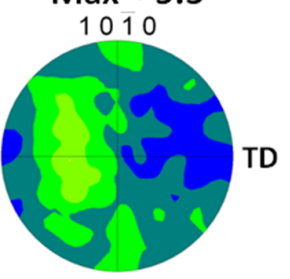

$\operatorname{Max} \approx 3.2$

Fig. 9 Orientation color map showing the microstructure of AS, SZ and RS (a, b, c) and the 
corresponding pole figures (d, e, f) of the AMX602 joint obtained by the asymmetrical DFSW at $500 \mathrm{~mm} / \mathrm{min}$ travelling speed. The data were measured by EBSD at the AS-c (a, d), SZ-c (b, e) or RS-c (e, f) indicated in Fig. 10.

In order to examine the entire texture distribution of the asymmetrical DFSW joints, EBSD measurements were conducted at various locations through the thickness of the joints. The results of the $\{0001\}$ pole figures of locations at the AS, SZ and RS are summarized in Fig. 10. At the top surface (a), the texture distribution was similar to that of the one-sided FSW as shown in Fig. 8, although the direction of the concentration of $<0001>$ tilts to a few ten degrees below from the WD. When the measurement position reaches close to the center of the thickness (c, d), the orientation concentration was destroyed and the texture was randomized. It should be noted that almost all areas show the lower values of the maximum intensity of the orientation concentration, except for the upper (a) and lower (f) surfaces in the SZ. This means that the asymmetrical DFSW is useful to obtain a joint with a relatively random texture due to the turbulent metal flow by the asymmetrical layout of the double-sided tool. 


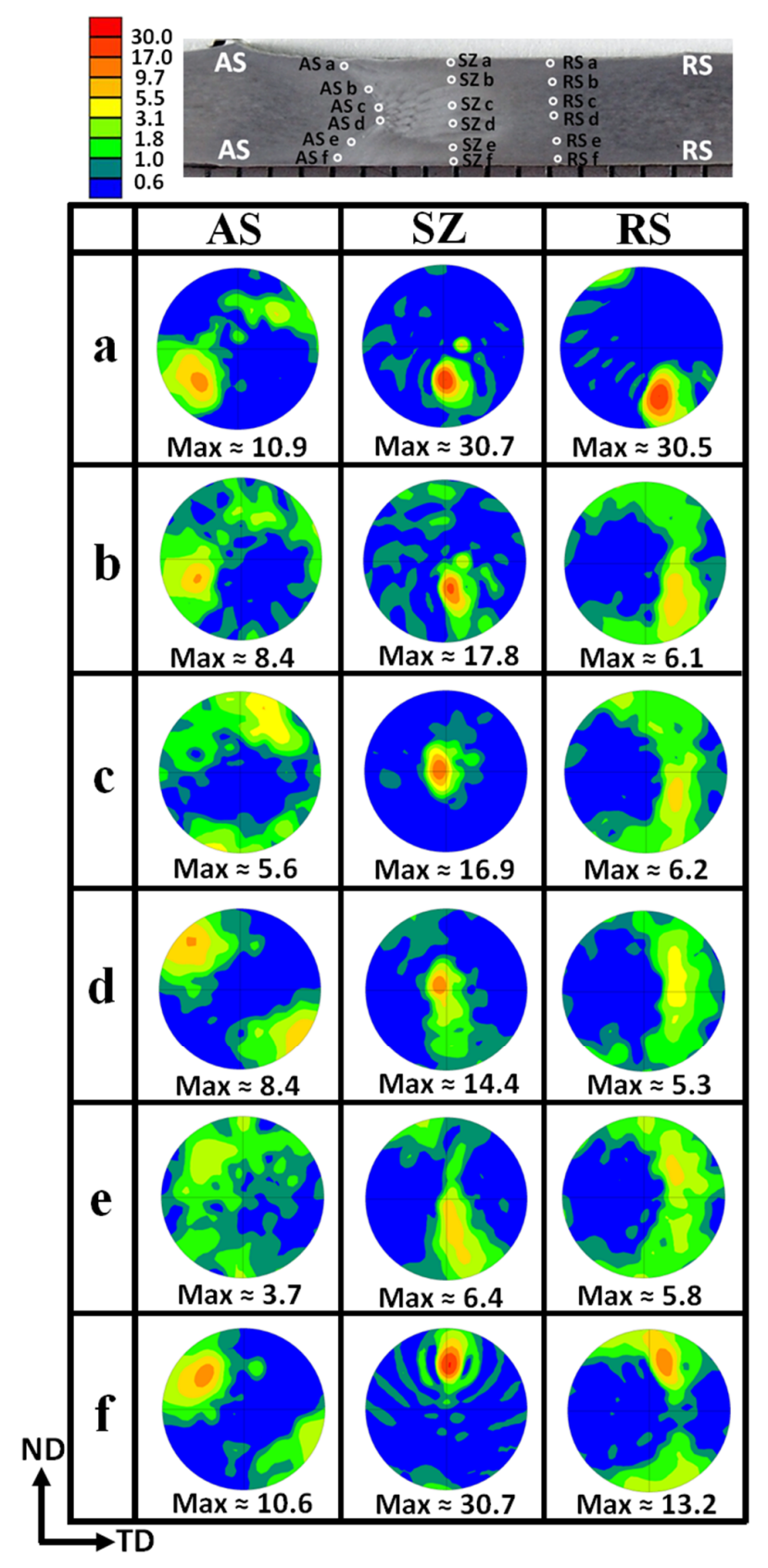

Fig. 10 The $\{0001\}$ pole figures of the various positions of the DFSW joint obtained at $500 \mathrm{~mm} / \mathrm{min}$ travel speed. The measurement positions are schematically illustrated at the top of this figure.

\subsection{Mechanical properties}

Fig. 11 shows the microhardness profiles measured along the mid-thickness line of the cross section of the one-sided FSW and the asymmetrical DFSW joints. The hardness of the stir zone in 
the one-sided FSW joint is slightly lower than that of the base material which has been described in a previous study (Chen et al., 2012). Additionally, the profile of the one-sided FSW joint shows an abrupt decrease from the base material to the stir zone at the edge of the probe. For the DFSW joint, a decrease in the hardness can be also found in the stir zone. However, it should be noted that the change in the hardness from the base material to the stir zone was more gradual than that in the one-sided FSW joint.

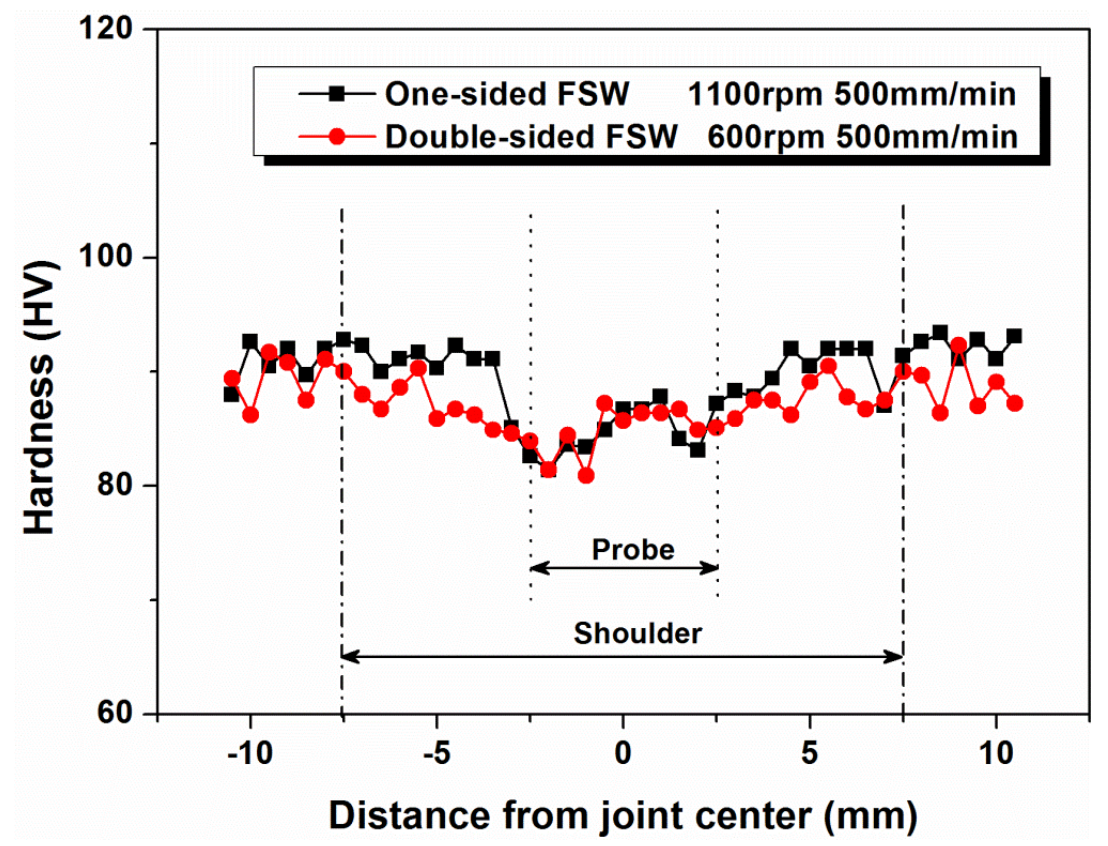

Fig. 11 Microhardness profile measured along the mid-thickness line of transverse cross sections of the FSW and the asymmetrical DFSW joint.

The transverse tensile properties of the base material, the one-sided FSW and the asymmetrical DFSW joints are shown in Fig. 12. The appearances of the side surface of the fractured specimens of the joints are also attached. The base material has an ultimate tensile strength (UTS) of $325 \mathrm{MPa}$, yield strength (YS) of $175 \mathrm{MPa}$ and elongation (El) of $7.6 \%$. Compared with the BM, the one-sided FSW joint showed UTS of $259 \mathrm{MPa}$, YS of $89 \mathrm{MPa}$ and El of $6.4 \%$, which mean that both the strength and the elongation decreased. This is due to the strong texture at the joint as was previously clarified (Chen et al., 2012). On the other hand, the asymmetrical DFSW joint has a higher tensile strength than the one-sided FSW joint. The joint obtained at the $500 \mathrm{~mm} / \mathrm{min}$ travel speed possesses 
UTS of $285 \mathrm{MPa}$, YS of $148 \mathrm{MPa}$ and El of $5.4 \%$. With respect to the fracture locations of the asymmetrical DFSW joint, the fracture did not happen in the TMAZ, which has a relatively random texture, by comparison with the one-sided FSW joint. Thereby, a higher tensile strength can be achieved.

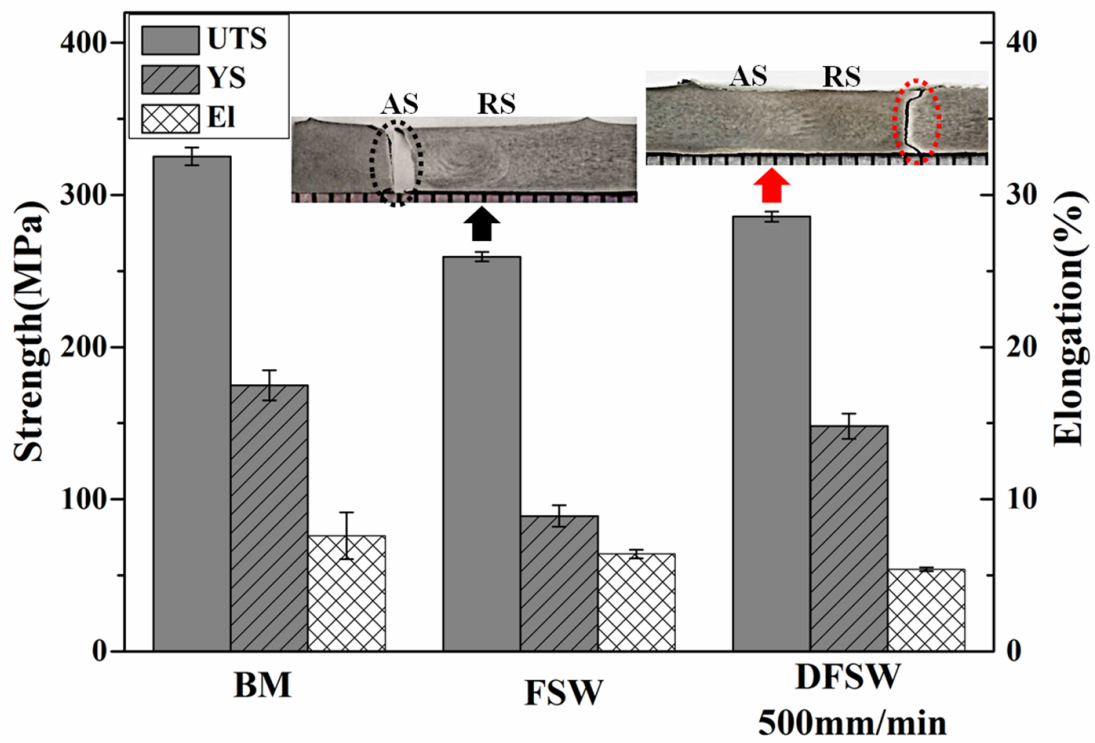

Fig. 12 Tensile properties of the base material, the FSW and asymmetrical DFSW joints. The side appearances of the fractured test pieces of the FSW and the asymmetrical DFSW joints are also shown.

\section{Conclusions}

The fine-grained non-combustive AMX602 (Mg-6\%Al-0.5\%Mn-2\%Ca) magnesium alloy prepared by SWAP had been successfully jointed by the asymmetrical Double-Sided Friction Stir Welding process which is the combination of tools with and without a probe. The microstructure, texture and mechanical properties of the asymmetrical DFSW joints have been evaluated. The main results obtained in this study are as follows:

(1) Due to the higher heat input of the asymmetrical DFSW, the oxidization of Ca happens at the butt interface during welding, and the joint defect forms as the prior interface residue. The prior interface residue is composed by a linear array of $\mathrm{Ca}$ oxide and the adjacent coarse grains with lacking of $\mathrm{Ca}$ solute. The prior interface residue was prevented by the appropriate welding 
condition $(500 \mathrm{~mm} / \mathrm{min})$.

(2) The DFSW successfully provides a relatively weaker texture than one-sided FSW in the entire region of the joints. This is due to the turbulence of the metal flow provided by the asymmetrical arrangement of the tools.

(3) The asymmetrical DFSW joint shows a superior strength with adequate elongation since the microstructure in the joints maintains a fine grained structure without any significant crystallographic isotropy.

\section{Acknowledgements}

The authors are thankful for the financial support of the project for heterostructure control from the Japan Science and Technology Agency (JST), the Priority Assistance for the Formation of Worldwide Renowned Centers of Research - The Global COE Program (Project: Center of Excellence for Advanced Structural and Functional Materials Design) and the Cooperative Research Project of Nationwide Joint from the Ministry of Education, Culture, Sports, Science and Technology (MEXT), Japan, and a Grant-in-Aid for Science Research from the Japan Society for Promotion of Science.

\section{References}

Arbegast W.J., 2008. A flow-partitioned deformation zone model for defect formation during friction stir welding. Scripta Mater. 58(5), 372-376.

Bohlen J., Nürnberg M.R.., Senn J.W., Letzi D., Agnew S.R., 2007, The texture and anisotropy of magnesium-zinc-rare earth alloy sheets. Acta Mater. 55, 2101-2112.

Chen J., Fujii H., Sun Y.F., Morisada Y., Kondo K., Hashimoto K., 2012. Effect of grain size on the microstructure and mechanical properties of friction stir welded non-combustive magnesium alloys. Mater. Sci. Eng. A 549, 176-184.

Chen J., Fujii H., Sun Y.F., Morisada Y., Ueji R., 2013. Fine grained Mg-3Al-1Zn alloy with randomized texture in the double-sided friction stir welded joints. Mater. Sci. Eng. A. 580, 83-91. 
Chen J., Ueji R., Fujii H., 2015. Double-sided friction-stir welding of magnesium alloy with concave-convex tools for texture control, Mater. Des. 76, 181-189.

Commin L., Dumont M., Masse J.E., Barrallier L., 2009. Friction stir welding of AZ31 magnesium alloy rolled sheets: Influence of processing parameters. Acta Mater. 57(2), 326-334.

Elsayed A., Kondoh K., Imai H., Umeda J., 2010. Microstructure and mechanical properties of hot extruded Mg-Al-Mn-Ca alloy produced by rapid solidification powder metallurgy. Mater. Des. 31(5), 2444-2453.

Hakamada M., Watazu A., Saito N., Iwasaki H., 2010. Dynamic recrystallization during hot compression of as-cast and homogenized noncombustible Mg-9Al-1Zn-1Ca (in mass\%) alloys. Mater. Sci. Eng. A 527, 7143-7146.

Hilgert J., Schmidt H.N.B., Santos J.F., Huber N., 2011. Thermal models for bobbin tool friction stir welding. J. Mater. Process. Technol. 211(2), 197-204.

Kim Y.G., Fujii H., Tsumura T., Komazaki T., Nakata K., 2006, Three defect types in friction stir welding of aluminum die casting alloy. Mater .Sci. Eng. A 415, 250-254.

Kondoh K., Elsayed A., Imai H., Umeda J., Jones T., 2010. Microstructures and mechanical responses of powder metallurgy non-combustive magnesium extruded alloy by rapid solidification process in mass production. Mater. Des. 31(3), 1540-1546.

Kumari K., Pal S., Singh S. B., 2015. Friction stir welding by using counter-rotating twin tool. J. Mater. Process. Technol. 215, 132-141.

Liao J.S., Hotta M., Mori Y., 2012, Improved corrosion resistance of a high-strength Mg-Al-Mn-Ca magnesium alloy made by rapid solidification powder metallurgy. Mater. Sci. Eng. A 544, 10-20.

Mishra R.S., Ma Z.Y., 2005. Friction stir welding and processing. Mater. Sci. Eng. R 50(1-2), 1-78.

Morisada Y., Fujii H., Nagaoka T., Nogi K., Fukusumi M., 2007, Fullerene/A5083 composites fabricated by material flow during friction stir processing. Composites: Part A 38(10), 2097-2101.

Park S.H.C., Sato Y.S., Kokawa H., 2003. Basal plane texture and flow pattern in friction stir weld of a magnesium alloy. Metall. Mater. Trans. A 34A, 987-994. 
Park S.H.C., Sato Y.S., Kokawa H., 2003. Effect of micro-texture on fracture location in friction stir weld of Mg alloy AZ61 during tensile test. Scripta Mater. 49(2), 161-166.

Sun Y.F., Fujii H., Takada Y., Tsuji N., Nakata K., Nogi K., 2009. Effect of initial grain size on the joint properties of friction stir welded aluminum. Mater. Sci. Eng. A 527, 317-321.

Thomas W.M., 1998. Friction stir welding and related friction process characteristics. Inalco 98 7th International Conference, joints in Aluminium, Cambridge, UK.

Thomas W.M., Nicholas E.D., Needham J.C., Murch M.G., Temple-Smith P., Dawes C.J., 1995. Improvements relating to friction welding. European patent specification $0615480 \mathrm{~B} 1$.

Wang Y.N., Chang C.I., Lee C.J., Lin H.K., Huang J.C., 2006. Texture and weak grain size dependence in friction stir processed Mg-Al-Zn alloy. Scripta Mater. 55(7), 637-640.

Xin R.L., Liu D.J., Shu X.G., Li B., Yang X.F., Liu Q., 2016. Influence of welding parameter on texture distribution and plastic deformation behavior of as-rolled AZ31 Mg alloys, J. Alloys Compd. 670, 64-71.

Yu Z. Z., Choo H., Feng Z.L., Vogel S.C., 2010. Influence of thermo-mechanical parameters on texture and tensile behavior of friction stir processed Mg alloy. Scripta Mater. 63(11), 1112-1115. 